\title{
O "relato de vida" como método das ciências sociais
} Entrevista com Daniel Bertaux

\author{
Luciano Rodrigues Costa* \\ https://orcid.org/0000-0001-9711-639X \\ Yumi Garcia dos Santos ** \\ https://orcid.org/0000-0001-7121-2180
}

Daniel Bertaux é um sociólogo francês amplamente reconhecido na Europa e alhures por ter sistematizado o método de pesquisa qualitativa que chamou de etnossociologia. Nele, os relatos de vida constituem fontes de dados por excelência. Renomado pela obra Le récit de vie (Bertaux, 1997), sua abordagem foi introduzida no Brasil há quase quarenta anos por meio da publicação Destinos pessoais e estrutura de classe (Bertaux, 1979). Todavia, carece de uma “apropriação” por parte dos(as) cientistas sociais brasileiro(as) no que diz respeito ao método proposto, apesar do interesse frequentemente demonstrado no meio acadêmico brasileiro. Tal lacuna nos motivou a realizar a entrevista com Daniel Bertaux. Ajudados pela internet, o contato foi feito por e-mail, a ideia sendo vivamente acolhida pelo sociólogo. Nossas perguntas foram respondidas detalhadamente por escrito, o que nos coloca em contato não somente com sua metodologia, mas também com sua visão sobre a sociologia ${ }^{1}$. Boa leitura!

* Universidade Federal de Viçosa, Minas Gerais, Brasil.

** Universidade Federal de Minas Gerais, Minas Gerais, Brasil.

1. Além da entrevista, a tradução, o levantamento bibliográfico e as explicações em notas de rodapé foram realizados pelos entrevistadores. 
Luciano Costa e Yumi Garcia dos Santos: Vocêpoderia inicialmente falar sobre a sua formação acadêmica e trajetória profissional?

Daniel Bertaux: Tenho uma trajetória tão atípica quanto o recurso aos relatos de vida foi atípico na sociologia empírica quando tentei convencer meus colegas de sua legitimidade. De fato, fui orientado por meus pais para uma formação científica de alto nível: obtive meu BAC $^{2}$ aos dezesseis anos, dois anos antes da idade normal (dezoito anos); eu me preparei para os concursos (difíceis, muito competitivos) de entrada nas Grandes Écoles, que na França constituem o nível de elite da educação superior. Em 1957, aos dezoito anos, passei no prestigioso concurso da École Polytechnique, da qual emerge a maioria dos principais administradores das grandes empresas industriais. Mas essa não era a minha vocação. Eu queria me tornar escritor. Meus pais sabiam disso, mas não levaram a sério. Além disso, quando saí da [École] Polytechnique em 1959, era a época em que todos os homens de vinte anos foram enviados para a guerra na Argélia (uma guerra suja). Eu nasci, sem sorte, em 1939, mas tentei escapar: a única maneira que encontrei foi escolher a carreira de engenheiro militar (na verdade, excepcionalmente o Exército não enviou à Argélia a elite de seus futuros engenheiros). Eu não gostava da profissão de engenheiro e odiava a hierarquia militar; mas tive que, com tristeza na alma, me envolver nisso por dez anos.

Quando voltei a Paris em 1963, precisei trabalhar como engenheiro militar; mas ainda consegui que me deixassem desenvolver as premissas da inteligência artificial. Meus superiores não acreditavam. Ao mesmo tempo, eu me matriculei no curso de sociologia na Sorbonne. Eu estudava à noite, mesmo sendo já casado e criando com Isabelle nosso primeiro filho, uma menina.

No entanto, um ano depois, ouvi falar de uma seleção que oferecia bolsas aos antigos estudantes das Grandes Écoles para rodar o mundo. Apresentei meu dossiê e em um golpe de sorte - sem intervenções particulares - consegui uma das quatro bolsas de estudo! Por isso, deixei, provisoriamente e com grande felicidade, um ofício de que não gostava para viajar, graças à Fundação Singer-Polignac, durante um ano na África do Leste, na Índia e no Nepal, depois na China e no Japão, na Califórnia e no México e, finalmente, no Peru, no Chile, na Argentina, no Uruguai (onde tenho família, Supervielle), no Paraguai e até no Brasil (São Paulo, Rio, Bahia etc.).

De volta a Paris, no começo de 1966, retomei meu trabalho como pesquisador em inteligência artificial (sobre a pattern recognition) enquanto estudava na Sorbonne e passava os exames de sociologia, demografia, economia política e psicologia social. E,

2. Bac ou baccalauréat é um título obtido por meio de exame ao encerrar o ensino médio e que dá acesso ao ensino superior. 
assim que me formei em sociologia, na primavera de 1967, candidatei-me ao CNRS como pesquisador em sociologia. Raymond Aron, que conhecia meu pai, não entendia por que eu deixava uma boa carreira de engenheiro militar, que estava se abrindo para mim, para entrar no CNRS com um frágil contrato. Mas ele me apoiou. Entrei para o CNRS direto, porque o establishment da sociologia francesa queria mostrar que "a sociologia é uma ciência como as outras ciências" (como Bourdieu escreveu um pouco mais tarde: é óbvio que isso é uma completa aberração). Quando cheguei, precedido pela aura da minha formação em ciências "exatas” e sua linguagem, a matemática, me abriram as portas e disseram: "Com seus conhecimentos científicos você nos ajudará poderosamente a adquirir o status de disciplina científica!". Eu perdi um terço do meu salário e fiquei totalmente eufórico!

Entrei no laboratório dirigido por Raymond Aron, que me confiou a Bourdieu. Trabalhei muito seriamente, estudando os fluxos estatísticos da mobilidade social, propondo algumas inovações, como o conceito de mobilidade estrutural. Mas sozinho. Bourdieu não me convidou para entrar em seu primeiro círculo (Boltanski, Chamboredon etc.). Depois de dois anos, Raymond Boudon, que montou seu próprio centro de pesquisa, veio me procurar. Bourdieu - que desprezava Boudon e, na verdade, todos os outros colegas de sua geração, exceto Passeron - me disse, no entanto: "Não te culpo, você foi leal". Leal? Eu entendi apenas anos mais tarde o que significava o uso desse termo: eu acreditava (ainda acredito) nos ideais do conhecimento e da pesquisa puramente científica, eu não tinha entendido que caíra no meio de uma guerra cruel de clãs entre antigos Normaliens: Bourdieu versus Boudon versus Touraine.

LC e Ys: Quem são os autores ou quais são as escolas de pensamento que influenciaram sua formação acadêmica?

DB: Estes não são os autores que nossos professores nos pediram para ler: Durkheim, Weber (dificilmente traduzido e mal). É um autor que eu mesmo escolhi: Marx. Houve movimentos estudantis massivos em maio de 1968, depois a grande greve operária de maio e junho (dez dias de greve geral em nível nacional que me marcaram). Depois da derrota eleitoral da esquerda e do restabelecimento da ordem (que de repente assumiu uma nova face, a de uma ordem de classe profundamente injusta), eu parei de ler a imprensa durante um ano e li Marx. Vinte páginas por dia. Mergulhar em um autor, dia após dia, não é apenas apropriar-se de seus escritos: é devolver ao próprio cérebro, ao próprio pensamento, uma coerência, uma unidade de espírito (e de espírito crítico) que a leitura de jornais diários tende, ao contrário, a atomizar e a enfraquecer. 
Então, primeiro Marx. Seus pensamentos - e ele mesmo como uma personalidade histórica - foram atacados por todos os lados. O partido da Ordem - o conservadorismo em toda parte - falava muito mal dele, a mídia o difamou descaradamente, cinicamente, tendo-o julgado, de uma vez por todas (e com razão), como incompatível com os "valores conservadores". Mas o verdadeiro paradoxo é que, finalmente, foi o leninismo que mais o feriu. Na época, a grande maioria dos jovens franceses (mas também americanos, italianos, alemães etc.) que sonhavam com a revolução social e militavam em organizações trotskistas ou maoístas liam Marx, mas especialmente Lênin. Porém, eles não viajaram. Eles sequer liam em inglês. Eu que era mais velho mas, especialmente, que tinha viajado e já falava quatro línguas, incluindo um pouco de russo - o que me valeu ser enviado pelo CNRS, a meu pedido, por dois meses à URSS para fazer contatos com os novos sociólogos russos -, que era simpatizante desses movimentos, como muitos intelectuais franceses da época (Sartre, Foucault etc.), eu tinha aprendido com um amigo, demógrafo húngaro, que a expressão "marxismo-leninismo" foi inventada pelo próprio Stalin. Isso abriu meus olhos. Como conciliar as minhas mais profundas convicções democráticas, autogestionárias (que, eu esperava, iriam conseguir encontrar a fórmula que combinaria liberdade, liberdades e equidade, até igualdade), com o fato de que todas as experiências de revoluções leninistas conduziam para o mesmo resultado: o poder discricionário de um só homem, o chefe do partido "revolucionário" que se tornou chefe de Estado? Isso já aconteceu na Rússia, na China, em Cuba, no Vietnã, na Coreia (do Norte), na Albânia etc.

Há com isso, para o sociólogo generalista que sou, uma questão muito importante para a qual procurei em vão a resposta durante toda a minha vida. Inacreditavelmente, os cientistas políticos contemporâneos não dizem nada sobre isso: eles se referem a Maquiavel, como se não pudéssemos ir além. Mas também é o ponto cego do marxismo: a "questão do poder", a questão da organização, da tensão entre eficácia e democracia, das lutas políticas e das relações de poder, das dinâmicas de concentração, como disse Michels (1971).

Voltando à sua pergunta inicial: entre as escolas de pensamento que me influenciaram, é claro que se deve mencionar o estruturalismo de estilo francês. Ele apareceu nos anos 1960 em pequenos círculos de estudos filosóficos, especialmente em torno de Althusser na École Normale Supérieure. Entra-se nesta “Grande École” somente se está entre os primeiros cinquenta selecionados no concurso de entrada extremamente seletivo. Passaram quase todos os grandes intelectuais franceses: Sartre, Foucault, mas também os maiores filósofos (inclusive Althusser, Rancière), historiadores (os da EHEss, bem conhecidos no Brasil), antropólogos (Lévi-Strauss, Godelier), sociólogos (Touraine, Bourdieu, Passeron, Boudon, Baudelot etc.). 
Este não é o lugar para desenvolver o pensamento estrutural. Eu diria apenas que ele está no cerne do pensamento científico do mundo inanimado (Newton entendeu por que as maçãs caem, assim que ele teve esta iluminação: parar de considerá-las como "sujeitos" - as maçãs - e colocá-las em relação ao astro Terra) cujos cientistas procuram descobrir as leis: mas qualquer lei se expressa por uma relação entre duas ou mais quantidades físicas. Acrescentarei que, em relação ao mundo histórico social, o pensamento em termos de vínculos e relaçôes tem sido igualmente frutuoso e fecundo.

Vou dar apenas um exemplo, que escolhi porque me parece ao mesmo tempo fundamental para compreender o mundo contemporâneo e um dos seus segredos mais bem guardados. Este é o exemplo das classes sociais. Se os autores dos muitos manuais de sociologia (livros didáticos americanos - textbooks) realizassem bem seu trabalho, eles explicariam aos alunos os fundamentos do fenômeno das classes sociais, constitutivo das sociedades industriais e pós-industriais, constitutivo da modernidade e da hipermodernidade. Esse é o fenômeno que está no cerne do "capitalismo" (no cerne do modo de produção especificamente capitalista, aquele que finalmente conquistou se não o planeta inteiro, pelo menos a totalidade de suas partes mais desenvolvidas).

Em vez disso, a maioria dos escritores de livros didáticos de sociologia - e, sobretudo, os acadêmicos americanos escritores de livros didáticos (textbooks), de um nível geralmente desolador - preferem contornar a "difícil questão das classes sociais: quantas são elas, como elas são definidas, pode haver classes sem consciência de classe? Ainda existem lutas de classes? etc." Eu coloquei aqui em palavras o profundo embaraço de um número muito grande de sociólogos contemporâneos de quase todos os países nos quais há um pensamento sociológico relativamente independente do poder. Eles cresceram em um contexto discursivo - como dizia Michel Foucault para designar o conjunto de ideias, representações, valores, crenças de uma sociedade em um dado momento de sua História -, o que os convenceu de que Marx e seu pensamento estão agora mortos, que ambos pertencem a um tempo passado, o do século XIX, o século industrial; que o mundo mudou muito desde então. Ninguém - pensam eles - contesta que a economia de mercado - market economy (o nome usurpado da forma contemporânea, financeira, portanto, do modo de produção capitalista) - invadiu o mundo inteiro, inclusive a China, e que esse modo de organizar as atividades econômicas permitiu que um grande número de países emergisse de um subdesenvolvimento multissecular para entrar na "modernidade".

Em outras palavras, se eu resumir: com a hegemonia da economia de mercado, as "desigualdades" aumentaram, mas (muito curiosamente) as classes sociais no sentido antigo quase desapareceram. Lembro-me de uma conversa com um colega, um sociólogo francês comunista, na qual eu disse a ele que, depois de ter estuda- 
do a questão das classes à luz do mundo contemporâneo, cheguei à conclusão de que "uma classe e somente uma classe existe plenamente e o tempo todo"; e ele a se aventurar: "A classe trabalhadora?" "Claro que não, camarada! A única classe que tem uma existência permanentemente, uma existência plena e inteira, não só na plena consciência cínica de seus interesses econômicos e políticos e do que fazer para defendê-los, mas também e, sobretudo, através de sua atividade prática, diária de classe dirigente/dominante, é evidente: a classe 'dominante e governante', esse núcleo duro de dirigentes e/ou proprietários das maiores empresas privadas, hoje em grande parte multinacionalizadas".

Então, o que dizer das "classes sociais no capitalismo de hoje" (título de um dos livros do falecido Nicos Poulantzas, que tentou esclarecer a questão usando estudos empíricos)? Elas definitivamente desapareceram ou elas ainda têm uma existência latente ou real? As respostas a essas duas perguntas são (na minha opinião) muito claras. Elas possuem dois pontos.

Em primeiro lugar, qualquer questão ou afirmação que coloque "as classes sociais" no plural é muito mal formulada, porque na realidade são formas sociais que não são apenas muito diferentes, mas, de certo modo, estruturalmente diferentes. Como escrevi em Destinos pessoais e estrutura de classe: para uma critica da antroponomia politica, "as classes" não são bolas de bilhar de cores diferentes (No Brasil, publicado pela Zahar: Bertaux, 1979; traduzido para o português por José Saramago - em Portugal, Edições Morais: Bertaux, 1978). São geradas, produzidas, reproduzidas e transformadas pela dinâmica da relação central que estrutura o modo de produção capitalista, a relação capital/força de trabalho que constitui a relação de classe central. O motor que faz rodar e em torno do qual giram os conjuntos sociais ("as sociedades").

O segundo ponto é, portanto, que se é impossível dar uma resposta clara à questão: “Existem classes sociais e quantas são elas?”, porque é extremamente mal formulada, pode-se, ao contrário, afirmar com uma certeza quase total que a relação de classe central do modo de produção capitalista, essa relação de classe não só existe realmente, mas agora é o eixo a partir do qual gira permanentemente e com uma velocidade cada vez mais rápida toda a economia do planeta.

LC e Ys: A perspectiva etnossociológica é muito pouco conhecida no Brasil. Vocêpoderia explicar seus princípios?

DB: Criei o termo "perspectiva etnossociológica” no momento da publicação da primeira edição do meu livro curto Le récit de vie (Bertaux, 1997). É um livro etnográfico/sociológico. Eu queria que o leitor compreendesse que a abordagem empírica que eu descreveria nesse livro resultava de uma combinação a priori improvável, mas 
que provou sua fertilidade heurística quando a implementei e a testei com sucesso em vários estudos com pesquisa empírica nos anos 1970, 80 e 90. É a combinação de uma técnica de observação empirica, o relato de vida, emprestada da grande tradição etnográfica e, de alguma forma, importada para ser usada na pesquisa sociológica (o estudo das sociedades desenvolvidas). A combinação dessa técnica empírica, portanto, com uma vontade determinada e feroz de compreender sociologicamente "objetos" sociais, isto é, "objetos empíricos" - como os mundos sociais no sentido de Howard S. Becker (1982) - que fazem parte de uma sociedade desenvolvida (neste caso, a sociedade francesa, mas também, por exemplo, a sociedade russa; ver: Bertaux e Malysheva, 1994, em francês - 1997, em inglês - on-line no site daniel-bertaux.com).

O termo "etnossociológico" (o significante) foi uma inovação, e é normal que não o entendam no Brasil ou em outro lugar, mas a ideia que ele procurou expressar (seu significado) não era nova. As pesquisas da primeira Escola (sociológica) de Chicago (Thomas e Znaniecki, 1918/1996; Clifford Shaw, 1972, etc.; ver também: Bertaux e Bertaux-Wiame, 1976) são exemplos notáveis dessa abordagem ou perspectiva, que descobri apenas por volta de 1975-76, quando eu escrevia o famoso Relatório ao Cordes $^{3}$ (Bertaux e Bertaux-Wiame, 1976). Antes eu nunca tinha ouvido falar dela durante meus estudos de sociologia. É mais o termo equivalente da antropossociologia que parece se impor pelo uso (Juan, 2015). Não importa o termo, desde que a ideia dessa combinação fértil seja destacada.

$\mathrm{Na}$ França, quando comecei a trabalhar nessa perspectiva, escolhendo estudar (como "objeto empírico") a padaria artesanal, sobre a qual eu não sabia absolutamente nada - mas estava ciente do valor simbólico do "pão diário" -, não foi de forma alguma sugestão dos meus sucessivos diretores de pesquisa (Pierre Bourdieu, depois de dois anos Raymond Boudon, depois de três ou quatro anos Alain Touraine). Pelo contrário! Bourdieu, que conhecia e apreciava a boa antropologia, cuidou de explicar ou mesmo endurecer a fronteira entre as disciplinas. Boudon tinha pouca predisposição para as pesquisas empíricas. Touraine tinha seu próprio jeito de abordar os movimentos sociais. Esses três, que juntamente com Crozier mantiveram firme toda a sociologia enquanto desenvolviam polêmicas muito violentas entre eles, estavam muito longe de reconhecer qualquer valor para uma perspectiva que combina uma abordagem empírica, inspirada (parcialmente) pela etnografia, e uma maneira muito sociológica. Para mim, significava implementar as descobertas de Marx, por exemplo, no estudo da padaria artesanal, concentrar a atenção na relação de produção (e de

3. Cordes: Comité d'Organisation de Recherches appliquées sur le développement Economique et Social (Comitê de Organização de Pesquisas aplicadas sobre o Desenvolvimento Econômico e Social), vinculado ao Commissariat Géneral du Plan (Comissariado Geral do Planejamento), do governo francês; financiou pesquisas nos anos 1970 . 
"exploração") entre os artesãos-chefes e "seus" trabalhadores padeiros (cuja existência eu tinha acabado de descobrir), uma maneira inteiramente sociológica de se questionar a partir de observações: por exemplo, perguntar-se "como isto funciona", "por que isto resiste", sendo o "isto" este setor de produção artesanal cuja própria existência, a resistência à concorrência da padaria industrial, era um enigma (em outros países industrializados, como a Grã-Bretanha, os Estados Unidos, o Canadá ou a Rússia Soviética, a padaria tradicional havia desaparecido fazia muito tempo).

LC e YS: O queéo método do relato de vida e como se relaciona com a etnossociologia? Como você a desenvolveu? Existe algum tipo de objeto com o qual o método seria mais eficaz?

DB: Sim, precisamente. Da mesma forma que há um tipo de objetos particularmente adaptados à pesquisa por questionários padrão em uma amostra estatisticamente representativa (o survey). São objetos sociais, coextensivos a toda uma "sociedade", ou melhor, à sua população. Por exemplo, as atitudes políticas ou morais ou as crenças ou as representações dessa população (mais exatamente, sua distribuição de acordo com os ambientes sociais, as regiões, as gerações etc.). Sabendo que essa forma de pesquisa "quantitativa" tem a capacidade de fornecer não apenas informações sobre as distribuições estatísticas, como também associações estatísticas entre "variáveis" que, em alguns casos, podem indicar a presença ativa de "relaçôes causais" mas sem poder saber mais sobre as mediações entre "causas" e "efeitos". Devemos retornar aos textos de Paul Lazarsfeld, um bom sociólogo que conhecia bem a diferença entre os dois.

No que concerne à perspectiva etnossociológica, ela consiste, pelo contrário, em procurar descobrir o "como isto funciona" de uma peça ou um pedaço coerente do grande mosaico societal. Se esse for um macrocosmo, ele é composto por várias centenas de mesocosmos - por exemplo, os setores de atividade (indústrias, serviços etc.), cada um se estendendo por todo o país e composto, por sua vez, por muitos microcosmos que são - como as padarias tradicionais ou, por exemplo, os hotéis turísticos de que a indústria do turismo é composta - todos eles estruturados mais ou menos pelas mesmas configurações de relações socioestruturais, pelas mesmas lógicas de situação correspondentes aos diferentes estatutos e lugares que geram sua estruturação específica, todos (os microcosmos) regidos pelas mesmas lógicas de funcionamento e as mesmas dinâmicas de reprodução e transformação.

Não desenvolvi suficientemente a teorização dessa grande ideia. Eu só posso dar exemplos. Mas esta é mais ou menos a mesma ideia que a dos mundos da arte de que fala H. S. Becker (1982), que são exemplos do que ele geralmente chama de "mundos sociais". Quando Becker toma o exemplo do mundo da música clássica, ele explica que esse mundo inclui não apenas os maestros e músicos profissionais, mas também 
os organizadores de concertos, os críticos de música, as associações voluntárias de amantes da música clássica etc. e até os que carregam o piano de cauda no palco da sala de concertos. Todos esses agentes participam da produção "ao vivo", da distribuição/comercialização e do consumo da atividade da música clássica. Há coerência nesse mundo social. Ele é governado por regras específicas, não escritas, conhecidas apenas por pessoas iniciadas, pelas lógicas internas (de carreira, de concorrência, de lucratividade, de sucesso e fracasso pessoais etc.) que se trata de descobrir. E a observação etnográfica direta mas também o estudo de documentos, de estatísticas, constituem tantos meios de tentar saber o que está acontecendo, como está ocorrendo e, finalmente, "como isto funciona".

Não é a pesquisa por questionário que permite descobrir essas lógicas internas de funcionamento. São técnicas emprestadas da tradição etnográfica. Etnográfico, não etnológico: o que a pesquisa sociológica requer são técnicas descritivas, modos de observar as realidades sócio-históricas que possibilitam descrever as configurações, os principais traços (the main features, as características), os mecanismos geradores, os processos recorrentes (que são sequências recorrentes de situações e ações).

O enfoque etnográfico sociológico (eu deveria tê-lo chamado assim) ou socioantropológico se aproxima, de certa forma, da abordagem de um jovem amante de mecânica de automóveis que se dispõe a desmontar peça por peça o motor de um carro velho para entender "como isso funciona": o carburador, a embreagem, o gerador, o circuito elétrico de distribuição etc. O problema dos sociólogos quantitativos é talvez que não parece interessar-lhes abrir o capô.

Mas cuidado com a metáfora do automóvel: uma sociedade é outra coisa do que um motor ou uma máquina projetada por uma equipe de inventores para funcionar perfeitamente. É um organismo vivo construído em torno de uma relação de classe intrinsecamente em tensão, ao redor do qual se proliferaram excrescências mais ou menos funcionais (existem peças ou partes claramente parasitárias), também governadas por relações de poder tomando formas específicas (elas não são governadas diretamente por uma lógica capitalista, é o caso das administrações estatais, das universidades e das outras instituições públicas - assim como o sistema francês de Previdência Social, uma notável máquina de seguro mútuo disponível às pessoas que residem na França, cidadãos ou estrangeiros, para se curarem com baixo custo); um organismo dotado além disso, como afirma Anthony Giddens (2003), de reflexividade: de uma capacidade de refletir sobre si mesmo.

Todo o problema é então saber como cortar, nesse macrocosmo, mesocosmos coerentes. No meu livro Le récit de vie (Bertaux, 1997), dou algumas indicações: os mundos sociais constituem conjuntos coerentes; mas também o que chamei de categorias de situação; e acrescentei - por sugestão de Catherine Delcroix - os fluxos 
de trajetórias, particularmente de migrantes. Há muito tempo que o Brasil tem sido um país de imigrantes livres, vindos de diferentes países europeus, mas também do Japão, por exemplo; e os africanos forçados a se deslocarem, contra sua vontade. Nós sabemos exatamente o que significa a imigração.

Mas deixe-me insistir na noção de coerência. Pode-se pensar, por exemplo, que a situação de lone mother, de mãe "solo" ou "solteira" criando sozinha seu ou seus filhos, sem o apoio do pai (ou de outro homem), é um exemplo típico de uma categoria de situação. Na minha opinião, esse não é o caso. No Brasil, na França ou em outros países desenvolvidos (e provavelmente também em outros, que eu conheço menos), a situação da mãe solteira, além de ser estigmatizada em alguns países por causa da religião, constitui uma situação economicamente difícil ou ainda impossível de viver. É de fato necessário que a "família" (household) constituída pela jovem mãe e seu bebê ou sua criança pequena tenha uma renda (income). No entanto, se o pai não paga uma pensão alimentar, como a jovem mãe pode ao mesmo tempo ter um emprego remunerado e cuidar do seu bebê ou da sua criança?

Essa é uma situação extremamente restritiva e, porque aprendemos com Durkheim (1894) que o social é antes de qualquer coisa coercitivo (o social também é constituído de oportunidades), a situação da mãe criando sozinha seu filho deveria ser um arquétipo de uma situação social. Porém, na minha opinião, se isso é principalmente o caso, nem sempre é o caso.

A situação social verdadeiramente restritiva é a de uma jovem de familia pobre que teve um filho de um homem que decidiu não assumir suas responsabilidades como pai, e ela não encontrou outro homem (ou até mesmo uma mulher) para substituí-lo como breadwinner. Essa situação específica parece não ter saída, contudo ainda assim é vivida por grande número de jovens mulheres em todo o mundo. Mas não na França nem na Suécia ou em outros países escandinavos. Nesses países, a jovem mãe recebe subsídios mensais de licença maternidade que lhe permitem dedicar-se plenamente por vários meses a seu bebê. Depois, ela pode conseguir um lugar na creche de seu bairro para seu filho até que ele/ela atinja a idade de três anos. Ele/ela é cuidado/a por educadoras, enquanto a mãe é, de algum modo, "liberada" das obrigações de mãe e, portanto, "livre" para trabalhar por um salário. Quando a criança atinge a idade de três anos, a mãe irá matriculá-la na "école maternelle" (ensino pré-escolar) do seu bairro. O sistema do ensino pré-escolar na França é de excelente qualidade.

Portanto, é possível definir uma categoria de situação somente após examinar cuidadosamente os parâmetros que constituem essa "situação". Catherine Delcroix e eu estudamos a situação de um pai divorciado (ou não casado, mas separado da companheira com quem teve um filho). Uma pesquisa estatística nacional sobre o modo de vida de crianças nascidas na França mostrou que uma grande proporção delas 
vivia com apenas um dos pais (a mãe, na maior parte do tempo) e que a metade delas só via o outro pai (neste caso o pai) menos de uma vez por mês, até nunca viam. Esse número foi a priori chocante: mas por que foi assim? Obtivemos da Caixa Nacional de Subsídios Familiares (Caisse Nationale des Allocations Familiales - CNAF) o financiamento para uma pesquisa etnográfica sociológica que permitiu compreender as razões dessa "retirada" dos pais.

Inicialmente pensamos que a "modernização" da sociedade francesa estava passando por uma individualização generalizada e que, de acordo com a teoria proposta pela socióloga feminista americana Barbara Ehrenreich em The hearts of men (Penguin, 1987) explicitamente subintitulado American dreams and the flight from commitment (Os sonhos americanos e a fuga de responsabilidades), os homens franceses, com cerca de vinte anos de atraso com seus homólogos norte-americanos, também fugiram, pelo individualismo, de suas responsabilidades como pais (Ehrenreich, 1987). É verdade que eles estavam cientes de que o Estado francês viria suprir seu fracasso. Mas assim que Catherine, que estava fazendo a maior parte do trabalho de campo, conseguiu começar a encontrar alguns pais "faltosos", ela entendeu que nossa hipótese estava errada. Anteriormente, ela conseguiu encontrar, através da CNAF, um grupo de 22 mães solteiras do mesmo bairro urbano que se encontravam mais ou menos regularmente, e lhes pediu para colocá-la em contato com os 22 pais faltosos. Mas se algumas delas efetivamente perderam contato com o pai de seu filho (e contaram com Catherine para encontrá-lo), a maioria não queria ter nenhum contato "com esse cara". Nossa hipótese inicial entrou em colapso, na medida em que os poucos pais separados (pela mãe) de seu filho que Catherine havia conhecido choravam que não podiam vê-lo crescer; portanto, as mães desejavam ardentemente o rompimento da relação pai/filho.

No entanto, a manutenção ou a abolição dessa relação não dependia, no final, da vontade das mães (ou da dos pais), e sim de uma decisão de um juiz de Assuntos Familiares. Eles eram soberanos nesse assunto. Catherine os encontrou. O que ela descobriu foi que havia duas categorias. Os magistrados mais velhos, todos homens, eram muito conservadores e argumentavam com ela: "A Família, Senhora, é a célula básica de nossa Sociedade. Mas ela é ameaçada de todos os lados: as pessoas se divorciam ou vivem como um casal e têm filhos sem se casar. Nossa função, Senhora, como a entendemos nós os magistrados, é, portanto, pelo menos preservar o que resta da Família: a relação mãe/filho. Nós damos então todos os poderes para a mãe". Por outro lado, a geração seguinte de magistrados, composta principalmente por mulheres (a profissão se feminizou consideravelmente), tinha um raciocínio completamente diferente: "Escute, na nossa sociedade ainda são os homens que têm todos os poderes: o poder econômico (as empresas são quase todas dirigidas 
por homens), o poder político (os deputados, os presidentes de região etc.), o poder administrativo etc. Para as mulheres, resta apenas um lugar onde elas podem ficar em pé de igualdade com os homens: nas relações com seus filhos. Então não vamos tirar isso delas!".

Em outras palavras, por razões quase opostas, a grande maioria dos juízes de Assuntos Familiares queria proteger o vínculo entre a mãe e seus filhos. Nessas condições não foi surpresa, finalmente, que uma boa metade dos filhos de casais separados ou divorciados perdesse o contato com seu pai biológico.

Do ponto de vista do método, nunca poderíamos ter esclarecido as razões profundas do fenômeno se tivéssemos feito a pesquisa usando um questionário padrão. Essa maneira de fazer pesquisas sociológicas combinando uma pesquisa de campo (necessariamente local, mesmo se multicampos) sobre objetos (fenômenos, processos etc.) com uma dimensão societal ainda não é bem compreendida ou aceita na França, nem bem entendida nos Estados Unidos (há exceções, como Michael Burawoy, cujo trabalho eu admiro muito). Por outro lado, Paul Atkinson e Bernard Hammersley (1990) espalharam seu espírito ${ }^{4}$ na sociologia britânica sob o nome Ethnography, simplesmente. Seu livro, que leva esse título, é um excelente livro didático.

Eu sinceramente acredito que o futuro da sociologia está deste lado. Não do lado dos surveys, que certamente fornecem informações úteis sobre a distribuição estatística de tal ou tal fenômeno em uma dada "sociedade" considerada em sua totalidade; porque os limites intrínsecos - por construção: built-in limits - do que um survey pode apreender são muito fortes. Curiosamente, falamos muito pouco desses limites. Mas eu não acho que podemos avançar na sociologia com coeficientes de regressão. Muitos colegas estão impressionados com a aparência "científica" dos modelos de regressão. Mas o semblante de matemáticas não é suficiente para tornar cientista. E para aqueles que conhecem um pouco sobre a história das ciências, da física em particular, as grandes descobertas são muito menos o resultado do rigor do que da imaginação dos pesquisadores. O rigor é uma condição necessária mas está longe de ser suficiente. É a imaginação que faz o verdadeiro trabalho, especialmente o de "romper com o senso comum", celebrado por Bourdieu, Chamboredon e Passeron (1999), em Le métier de sociologue - O oficio de sociólogo (que, apesar de seu cientificismo, é uma excelente introdução à epistemologia).

LC e YS: Como o relato de vida foi recebido na França e como você avalia seu uso nas pesquisas atuais?

4. No sentido de "pensamento". 
DB: Podemos muito bem fazer pesquisas em uma perspectiva etnográfica sociológica (procurando assim esclarecer um fenômeno social espalhado por toda uma sociedade, mas usando métodos de observação emprestados da pesquisa de campo etnográfica) sem recorrer à coleta de relatos de vida. Isso é o que a maioria dos sociólogos fez até agora. Eles sentem que estão perdendo alguma coisa? Não, de forma alguma: como eles perceberiam o que iriam sentir falta? Para percebê-lo, seria necessário refazer uma pesquisa sobre o mesmo objeto empírico, o mesmo fenômeno, o mesmo processo, mas desta vez incluindo a coleta de relatos de vida. Entenderíamos então tudo o que perdemos.

Entretanto, isso eu não consigo descrever em poucas frases. Nem por um ou dois exemplos, pois o que eu estou falando (o que perdemos se não incluirmos relatos de vida na panóplia de técnicas de observação que iremos implementar durante um projeto de pesquisa) é tão rico, diverso, considerável, que não pode ser descrito. Para imaginá-lo, seria necessário um mínimo de conhecimentos sobre as pesquisas que incluíam relatos de vida (quando Pierre Bourdieu, em 1986, escreveu o artigo "A ilusão biográfica" sobre o método de relatos de vida, artigo que ele queria o mais destruidor possível, estava claramente no nível zero desse tipo de conhecimento). Mas também precisaria de uma boa dose de imaginação, e esta não é a principal qualidade dos metodólogos.

Eu li muitos artigos de sociologia que descreviam uma pesquisa etnográfica sociológica baseada na observação direta. Por exemplo, os sociólogos com orientação "interacionista simbólica” trabalham assim. Eles descrevem bem a organização - por exemplo, a da sala de um grande restaurante ou a das suas cozinhas -, e isso é muito interessante. Mas nós não aprendemos nada sobre os homens e mulheres que trabalham lá todas as noites. De onde eles vêm? Qual é a sua história, quais são suas histórias pessoais? Não saberemos nada. Eles poderiam ser robôs.

Pior ainda, me parece, se o objeto estudado é do tipo movimento social ou movimento associativo. Alain Touraine queria ser o Marx do século Xx. Ele procurou descobrir a relação de classe na base da qual as sociedades pós-industriais foram construídas e desenvolvidas. Relações de gênero? Relação entre a tecnocracia central e os movimentos democráticos espontâneos contestando, por exemplo, a decisão do Estado francês de multiplicar as centrais nucleares (o exemplo japonês teria sido mais significativo). Ele estava interessado em dinâmicas sociais e tinha uma capacidade rara de analisar os "sistemas de ação histórica” em que vários atores estavam lutando em torno de uma questão muito central. Mas ele não estava muito interessado nos militantes dos movimentos sociais, exceto como atores temporários (embora muito mobilizados) desses movimentos; as razões pessoais que levaram alguém a se envolver profundamente não interessavam a ele. 
No entanto, percebo, escrevendo isso, que corro o risco de ser mal interpretado. Não é nem um risco, é uma certeza. O leitor acreditará de boa-fé entender que eu defendo o uso de relatos de vida para saber "o que as pessoas têm em suas cabeças". Mas o que eu quero mostrar é quase exatamente o oposto.

A maioria dos sociólogos que recolhem relatos de vida procura saber por esse meio o que este ou aquele ator tem em mente: como ele ou ela vê as coisas, quais são suas representaçôes mentais, quais são suas convicções (pessoalmente eu prefiro de longe esse termo ao de "valores", usado de forma abusiva), quais são as suas crenças etc. Quais são as suas Sinnstrukturen, as configurações semânticas que estão escondidas em sua mente? Não é, por acaso, que uso um termo alemão: a Alemanha é, desde Dilthey, a pátria dos relatos de vida, o país onde os sociólogos mais coletam e onde desenvolveram as técnicas de análise mais sofisticadas. Ulrich Oevermann foi o primeiro a desenvolver a ideia de uma "hermenêutica objetiva", a qual envolve a análise com várias pessoas, linha por linha ou, pelo menos, frase por frase, e durante vários dias se precisar, da transcrição de $u m$ relato de vida para identificar todos os significados que ele contém explícita $e$ implicitamente, ou poderia conter. É uma experiência excitante participar de tal análise em grupo. Há também Fritz Schütze, que passou décadas estudando a "biografia” como objeto do pensamento sociológico e propôs vários conceitos esclarecedores. Há Gerhard Riemann e seu trabalho sobre as trajetórias, além de muitos outros, incluindo Ursula Apitzsch, Lena Inowocki etc.

Mas esses pesquisadores têm uma forte tendência a analisar os relatos de vida um por um, separadamente uns dos outros. Isso não é uma particularidade germânica: ela é encontrada na Grã-Bretanha, nos Estados Unidos e até mesmo na França com o excelente trabalho de Maurice Catani e Suzanne Maze (1982) sobre "Tante Suzanne”. De que forma isso é um problema? Ao fazê-lo assim, por meio de estudos de casos individuais, os pesquisadores são orientados de fato - pela própria natureza de seus dados, um único relato de vida - para uma análise psicológica. Tenho profundo respeito pela psicologia, mas não é minha disciplina, nem mesmo a dos meus colegas. Um dos argumentos deles é que, às vezes, os Sinnstrukturen não existem apenas nas cabeças das pessoas, mas também "entre eles", nos discursos coletivos: esse argumento agrada ao (pós) estruturalista que eu nunca deixei de ser, porém é - de forma ideal da psicologia social, não da sociologia.

Diante dessa prática, muito difundida entre os sociólogos que ousam trabalhar com relatos de vida e que eu critico, qual é então o meu ponto de vista? Como usar os relatos de vida para fazer sociologia? A resposta está tão distante do "senso comum" dos sociólogos que precisei de cem páginas para explicá-lo (Bertaux, 2016). Só vou dizer aqui que não me contentei apenas com um argumento metodológico: testei 
por quase trinta anos, de 1969 a 1996, o método dos relatos de vida no contexto de vários projetos de pesquisa sobre objetos muito diversos (a padaria tradicional na França, as migrações do campo para a cidade, o enfraquecimento do vínculo pai/filho depois de um divórcio ou de uma separação, os processos de formação dos destinos socioprofissionais na Rússia durante os 75 anos de "comunismo"). Continuei então a experimentar o método em outros projetos de pesquisa, incluindo um projeto europeu de precariedade, no qual comparamos - entre outras coisas - a situação de mães solteiras (single mothers) em sete países da Europa Ocidental (da Suécia para Portugal, da Irlanda para a Itália etc.).

Eles eram tópicos de pesquisa que me interessavam, mas sobre os quais, a princípio, eu não sabia nada. Menciono isso porque é comum hoje em dia que os/as estudantes de sociologia escolham, para seu doutorado, por exemplo, estudar um assunto que os toca de perto. Se, por exemplo, uma deles fosse marciana e viesse estudar sociologia na Terra, ela escolheria como tema de seu doutorado a questão da adaptação das imigrantes marcianas ao modo de vida da Terra. Em outras palavras, a escolha de um assunto é muitas vezes (com demasiada frequência na minha opinião) orientada para o que alguém já acredita conhecer bem de sua experiência vivida. Escolha compreensível no mundo ultracompetitivo de hoje; mas não foi isso que eu fiz.

E isso pode ser precisamente - eu percebo escrevendo-o aqui mesmo - porque eu estava escolhendo objetos de pesquisa dos quais eu não sabia nada a priori: então, fui em busca de bons informantes que pudessem me dizer "como isso funciona" no mundo social (ou a categoria de situação ou o fluxo migratório), que eu queria estudar e entender sociologicamente.

Porque a minha ideia central é esta: ninguém conhece a "sociedade" como um todo, mas cada um de nós, cada pessoa tem um conhecimento e até uma profunda compreensão do mundo profissional em que ela ou ele trabalhou por muitos anos e/ou o microambiente social em que ela ou ele viveu. Assim, cada um tem nele/ nela saberes, conhecimentos com os quais o pesquisador em sociologia poderia fazer valer. Em O oficio de sociólogo (Le métier de sociologue), Bourdieu e Passeron (1999) escreveram esta frase: "Lidar com objetos que falam é talvez a maldição das ciências humanas". Apesar de todo o respeito que seus trabalhos me inspiram, acho que essa afirmação (statement) é tão incorreta quanto arrogante. Embora esteja claro que "as pessoas" - e eu me incluo entre elas - têm em grande medida ideias falsas - ou melhor, influenciadas pela mídia - sobre a maioria dos tópicos com que eles/elas não tiveram experiência direta, acho muito mais plausível perguntar a priori (mesmo para verificá-lo) que, quando se trata dos meios profissionais ou de outros ambientes em que eles trabalharam e / ou viveram e dos quais eles/elas tiveram experiência direta, eles sabem aproximadamente do que eles estão falando. 
São, portanto, seus conhecimentos (knowledge) de um mundo social específico e suas lógicas de funcionamento, conhecimentos adquiridos pela experiência vivida deste mundo (se substituirmos o "mundo social" por "situação socioestrutural", a afirmação permanece válida), que me interessam como sociólogo. Mas eu não vou imediatamente pedir a eles para transmiti-los: eles/elas não são sociólogos. Portanto, peço apenas que descrevam para mim sua experiência vivida nesse mundo social (ou nessa categoria de situação). Descobri que uma boa maneira de fazer isso é perguntar como eles entraram nesse mundo. Por exemplo: Como você se tornou um padeiro? Essa pergunta surge naturalmente para iniciar a entrevista, uma vez que, a partir do contato e da negociação de uma entrevista e de um encontro, a pessoa está ciente de que o sociólogo procura entrevistá-lo como (padeiro ou padeira, trabalhador de padaria etc.).

Isso também se aplica a uma pesquisa de relatos de vida de pessoas que viveram uma situação socioestrutural específica: todas sabem que é como (mãe solteira, pai divorciado, ex-prisioneiro, desempregado de longa duração, vítima de acidente de trabalho etc.) que o/a sociólogo/a gostaria de entrevistá-los.

É claro que os relatos da vida que obtemos desse jeito podem não ser "completos". Por exemplo, sabendo que a infância de uma pessoa quase sempre tem consequências sobre a trajetória de vida do adulto, o sociólogo pode ser tentado a fazer perguntas sobre a infância do entrevistado. Mas, como essa pergunta não aparece no acordo inicial “Como você se tornou..., o entrevistado pode (legitimamente) ser surpreendido e se recusar a responder. Teria sido melhor que ele imediatamente "contasse sua vida" ? Eu não penso assim; porque, se uma pessoa não quiser falar sobre sua infância, ela recusará esse tipo de entrevista; enquanto ela é suscetível de aceitar uma entrevista centrada em sua vida profissional.

Tudo isso parecerá contraintuitivo para um/a leitor/a que, pela primeira vez, aborda a questão dos relatos de vida na sociologia e imagina que um relato de vida "é como uma autobiografia improvisada ao longo de uma entrevista". O que está errado, não seria, porque uma entrevista biográfica tem sempre não só um autor, como qualquer autobiografia escrita, mas dois autores, e a "agenda" do segundo autor (que pode ser um sociólogo, mas também um psicólogo, um antropólogo, um psicoterapeuta, um assistente social etc.), isto é, o que ele/ela procura obter, conta na dinâmica e no decorrer da entrevista. Mas, como eu já disse antes, não quero repetir aqui o que detalhei longamente no meu livro.

Dito isso, permanece que, como observa Freud se referindo ao poeta Wordsworth, "The child is the father of man", a criança é o pai (e/ou a mãe) do adulto. E para as pesquisas sociológicas sobre certas temáticas, especialmente em tudo o que concerne às relações familiares na vida adulta, é quase indispensável fazer com que os/as 
entrevistados/as falem sobre sua infância. Porque os (jovens) homens que formam casais tendem, inconscientemente, a se comportar em relação a sua companheira como seu próprio pai se comportou em relação a sua mãe (não se esqueça de que eles não conheceram nenhum outro modelo familiar do que aquele em que cresceram). Isso também é verdade para as mulheres jovens. E isso é particularmente verdadeiro no relacionamento de uma mãe, ou de um pai, com seu/seus filhos: ela/ele tenderá, inconscientemente, a reproduzir as relações que sua mãe/pai teve com ele.

Volto à sua pergunta: "O que é o método dos relatos de vida?" Se vocês querem uma resposta direta, aqui está: não há UM (apenas) "método de relatos de vida". Existem vários usos de relatos de vida em diversas disciplinas das ciências humanas e sociais. E, mesmo dentro da sociologia, existem várias maneiras de conceber o uso de relatos de vida para fazer sociologia. Eu proponho uma maneira específica que, segundo entendo, tem várias características interessantes. Em primeiro lugar, não resulta das elucubrações na sala de um acadêmico em busca de reconhecimento: sou um pesquisador a tempo inteiro, sou apaixonado por pesquisa, procuro entender o mundo ao meu redor fazendo pesquisas empíricas. Não sou um sociólogo limitado a este ou àquele campo da sociologia, sou generalista; e é um trabalho sério, a tempo inteiro. Explorei um caminho difícil, desaconselhado e até mesmo proibido por todo o establishment da sociologia francesa. Eu me arrisquei e fiz descobertas muito contraintuitivas que merecem ser conhecidas. Demonstrei, a partir do exemplo de várias pesquisas empíricas sobre "objetos sociais" muito diferentes, que é possível usar relatos de vida para adquirir conhecimentos e uma boa compreensão sociológica desses objetos. Além disso, não o fiz sozinho, mas com vários colegas que conseguiram desenvolver os seus próprios trabalhos.

Mas quando se trata de usar os relatos de vida para fazer (boa) sociologia, o que vale a maneira específica que proponho em comparação com outras? Eu já disse isso antes: ela vale porque leva a concentrar seu "olhar mental" não no que as pessoas têm em mente (e que, eu sei, importa nas suas maneiras de agir), mas diretamente nas relaçôes sociais, ou, para dizer ainda melhor: nas relaçôes socioestruturais, nas relações entre lugares. Porque está aí, e em nenhum outro lugar, aí que é preciso procurar as lógicas de funcionamento e as dinâmicas de um dado "objeto social coerente": mundo social, categoria de situação, processo determinado etc.

Pode-se me dizer: "Mas se você não quer saber o que está na mente das pessoas, como você pode esperar entender sua lógica de ação?" Questão pertinente: mas Niklas Luhmann, entre outros, já respondeu muito bem. O que ele diz, na essência, é o seguinte: seja o caso de uma pessoa que realiza uma ação em um contexto "socializado": no contexto de seu trabalho ou de uma atividade coletiva ou recreativa. Imagine dois observadores: um conhece a pessoa (então, o que está em sua cabeça), 
mas não sabe absolutamente nada (digamos, que esteja no Japão) do contexto preciso em que a pessoa está fazendo uma ação. Para o outro observador, é o oposto: ele conhece bem e entende o quadro (organizacional, por exemplo) da ação empreendida, mas não conhece a pessoa em si. Luhmann faz a pergunta: qual dos dois tem mais probabilidade de prever corretamente o que ela fará? E ele responde: quem conhece o contexto, não aquele que conhece a pessoa, porque a maior parte das ações que realizamos são orientadas e guiadas pelos processos de reprodução autopoiéticos da nossa sociedade.

Eu penso a mesma coisa, com um vocabulário um pouco diferente, mas igualmente estruturalista e pós-estruturalista. E gostaria de acrescentar que Bourdieu também deveria ter pensado assim, se ao menos tivesse elaborado sua teoria do campo, que é excelente, antes daquela do habitus, que esclarece de maneira interessante um dos aspectos da ação (o peso da infância, do caráter eu diria), mas se torna um obstáculo real para a compreensão da ação, logo que ele (Bourdieu) procura reduzir as razões para qualquer tipo de ação ao habitus do ator; e isso é muito reducionista, como Bernard Lahire (1998) mostrou em L’homme pluriel. Penso que Bourdieu estava muito consciente das fraquezas de sua teoria da ação, inteiramente centrada no habitus, mas investiu demais nessa teorização para arriscar, ao expressar a menor dúvida, desencadear sua abrupta desvalorização e sua súbita e definitiva queda.

Em retrospecto, acho que posso dizer que o método específico que desenvolvi e que é detalhado no meu livro (para o qual eu havia proposto o título Os relatos de vida, já que na minha opinião sempre devem ser feitos vários, até o aparecimento de recorrências e, se possível, até o momento de saturação, mas o editor insistiu em pôr $O$ relato de vida, no singular) - que este método que desenvolvi pouco a pouco quase podíamos encontrá-lo diretamente (mas apenas em retrospecto). De fato:

- Depois de ter lido Les enfants de Sanchez (Lewis, 1963), obra de um antropólogo que, como tal, não tinha obrigação de generalizar, eu queria ver se poderíamos fazer sociologia com relatos de vida;

- essa "técnica” (de fato, é uma técnica) fazia claramente parte das "técnicas qualitativas". Portanto, caí no amplo campo da "sociologia qualitativa", na qual a questão da generalização é colocada de maneira muito diferente (e, além disso, de um modo muito mais interessante e que recorre mais à reflexão e à teorização) do que o campo de survey research;

- se na época eu tivesse ouvido falar (o que não era o caso) dos trabalhos dos sociólogos americanos que desenvolveram, em Chicago, essa questão da generalização a partir de dados “qualitativos", isto é, não quantitativos, eu teria encontrado muito antes, especialmente no notável trabalho de Barney Glaser e Anselm Strauss The 
discovery of grounded theory (1967), as ideias de recorrências e de saturação, em vez de ter de redescobri-las eu mesmo. Mas o fato de eu havê-los encontrado consolida seu status como pontos fortes da abordagem "qualitativa".

- A escola neointeracionista, de que faziam parte Barney Glaser, Anselm Strauss e Howard S. Becker (autor de famosas pesquisas qualitativas altamente inovadoras e, com Charles Ragin, de What is a case?, 1992), não usou os relatos de vida. De maneira geral, focalizou nas interações em situação e não procurou desenvolver a dimensão temporal. Até que, em sua pesquisa sobre os serviços hospitalares para pacientes que vão morrer em um tempo relativamente curto, eles desenvolvem o conceito de trajectory, no sentido de um segmento da vida durante o qual uma pessoa se encontra como sob os trilhos dos quais não pode escapar. A introdução de relatos de vida (life stories) no quadro teórico empírico do interacionismo foi um complemento que não desestabilizou, mas, ao contrário, enriqueceu essa abordagem. Além disso, dois estudantes alemães de Anselm Strauss, Fritz Schütze e Gerhard Riemann, ao retornar ao seu país, foram os primeiros a desenvolverem a coleta e a análise de relatos de vida e a "Biografieforschung". Mas com a tendência de analisar os relatos um por um, em vez de multiplicá-los, e procurar revelar as recorrências de um para o outro, para ir além do nível microssocial e alcançar o nível "mesossocial", o dos mesocosmos.

- O que eu propus é, portanto, em retrospectiva, manter o espírito da melhor maneira até agora para fazer sociologia, a partir de observações no campo, mas enriquecendo-a através da inclusão, na panóplia de técnicas empregadas, da dos relatos de vida. Porque os relatos de vida trazem consigo pelo menos três características dos atores: sua singularidade, sua historicidade, sua subjetividade (percepção e atividade semiautônoma), bem como leva em conta a dimensão temporal dos processos de funcionamento social do objeto estudado.

LC e Ys: Em sua obra Destinos pessoais e estrutura de classe (Bertaux, 1977; em português, 1978), vocêf fala de biografias e de suas relações com a mobilidade social e a estrutura de classe. Ela mostra sua crítica em relação ao neopositivismo e aos métodos quantitativos, afirmando que a sociologia deveria dedicar-se às produções sociais e às suas relaçôes (forjada no termo "antroponomia"). Como você concebe sua contribuição para pensar no caráter cientifico dos métodos etnográficos em sociologia?

DB: O trabalho que desenvolvi sobre os relatos de vida consistiu primeiramente em examinar se a coleta dos relatos de vida permitia perceber empiricamente as facetas do sócio-histórico que permaneciam invisíveis em outros métodos de observação. Levando em consideração a hostilidade generalizada em relação a essa "técnica", em 
particular por parte dos quatro sociólogos que mais ou menos controlavam toda a sociologia francesa, levei alguns anos para começar a falar disso publicamente; e apenas alguns raros jovens pesquisadores já mais ou menos marginalizados - como eu - mostraram algum interesse. Eu era pesquisador do CNRS, não lecionava, não tinha estudantes. Mas o meu relatório de 1976, intitulado Histórias de vida - ou relatos práticos?, em que falei notadamente de trabalhos de sociólogos da primeira "escola de Chicago" (Thomas e Znaniecki, Clifford Shaw...) que eu acabava de descobrir, circulou bastante (Georges Balandier quis publicar na coleção que ele dirigia na $\mathrm{PUF}^{5}$; mas ele me pedira para tirar algumas passagens polêmicas, não dei prosseguimento e me arrependi).

Aos poucos os estudantes vieram me dizer: "Pronto, coletei vários relatos de vida, o que devo fazer agora?”... Na época era complicado lhes explicar que eles/elas estavam colocando o carro na frente dos bois. Hoje eu lhes diria, e digo aos jovens sociólogos do Brasil e de alhures: "Vocês devem certamente possuir um celular com o qual podem filmar. Hoje em dia todo mundo pode filmar. Mas será que todo mundo se tornou cineasta? Bastaria filmar para fazer um filme? Para fazer cinema? Não? Então reflitam sobre o que faria a diferença...”.

Qualquer um que esteja munido de um gravador pode coletar um relato de vida; e, como escrevi no meu livro, esse relato não tem nenhuma necessidade de ser completo, pode ser a respeito de um só período da vida: no momento em que houver uma narrativa, "existe relato de vida", e é suficiente. Contudo, ainda não se faz sociologia com isso.

Portanto, a dificuldade não é de coletar um, dois ou três relatos de vida. Isso muita gente sabe fazer. É fazer de maneira que seja cumulativo; que a partir disso algo se construa. E, no que me concerne, algo de sociológico. E isso é muito mais difícil.

Mas uma outra maneira de utilizar os relatos de vida se desenvolveu igualmente desde o início da retomada do interesse pelos relatos de vida quarenta anos atrás. Ela consiste em coletar e analisar (apenas) um relato de vida. Eu poderia dar vários exemplos de artigos de revistas de sociologia centrados sobre somente um relato de vida, redigidos por colegas ingleses (Michael Rustin, por exemplo), americanos, canadenses, suecos, italianos, suíços, japoneses; e sobretudo colegas alemães, dos quais os exemplos de análises de um (só) relato de vida são tão grandes que perdemos a conta. Podemos considerar que tal maneira de proceder é mais usual do que o que eu proponho. De fato, se levarmos em consideração o conjunto de disciplinas que interessam aos relatos de vida, ela é muito mais conhecida do que a minha. Tomamos de fato a psicologia: ela procede evidentemente pelos estudos de casos individuais. 
O/a psicólogo/a vai longamente escutar uma pessoa lhe contar sua vida, e refletir em particular sobre a maneira como ela contou, sobre as significações implícitas, sobre o sentido oculto de certas frases... de certos silêncios...

Mas com que fim? É evidentemente para tentar descobrir a chave da sua personalidade, da sua subjetividade, da sua psique. Quando finalmente encontramos a chave, compreendemos muito melhor a pessoa. Mesmo se eu digo de uma maneira que parecerá sem dúvida ingênua a um(a) psicólogo(a), é disso que se trata. Não se trata de procurar explicar os fenômenos psíquicos várias vezes observados cuja causa ainda não foi encontrada, sua gênese... Trata-se portanto, para o especialista, de compreender esse caso individual específico; para em seguida tentar ajudar essa pessoa a melhorar. Não se trata, pois, de uma pesquisa, mas definitivamente de uma terapia.

Outras disciplinas também utilizam os relatos de vida para fins práticos. Por exemplo, nas ciências da educação ou em cursos supletivos, desde algumas décadas e em vários países têm-se formado pequenos grupos cujos participantes são convidados a contar sua vida. O pano de fundo teórico aqui é constituído por uma tentativa - talvez sem saída - para articular psicologia e (micros)sociologia, Freud e (talvez) Mead; evoluímos no quadro da psicossociologia. Gosto muito da frase do meu colega e amigo Vincent de Gaulejac: "O indivíduo é produto de uma história de que ele procura ser o sujeito". E ele pelo menos multiplicou os relatos de vida e as experiências de pequenos grupos de meios bem precisos, os quadros superiores de empresas privadas. E as "profissões intermediárias", tais como trabalhadores sociais, animadores, formadores de adultos... Ao se concentrar em determinados meios socioprofissionais, ele se deu talvez a possibilidade de revelar as recorrências e de extrair algumas hipóteses sociológicas plausíveis. Mas não é o caso da maioria de pesquisadores, seja qual for a disciplina: se estudamos apenas casos isolados uns dos outros, caso por caso, seríamos fatalmente conduzidos a apenas análises e resultados psicológicos. Ou talvez, no melhor dos casos, a resultados psicossociológicos; mas, em todo caso, não a resultados sociológicos.

No mundo contemporâneo, é nos ares germano-falantes (Alemanha, Áustria, Suíça alemã) que o recurso ao relato de vida é o mais utilizado. É lá também que sob a influência dos trabalhos de Fritz Schütze, um sociólogo e sociolinguista capaz de reflexões profundas, que se desenvolveu no além-Reno a Biografieforschung, a "pesquisa biográfica". Schütze pensa que "a biografia" (que ele entende, me parece, no sentido de "percurso de vida individual que se forma na durabilidade") constitui um objeto de pesquisa legítimo para um sociólogo; que se pode de algum modo descobrir os processos ("estruturais", acrescenta) que estariam presentes em todas as "biografias", em todos os percursos biográficos (quanto a mim não estou totalmente convencido de que processos similares podem ser encontrados nos percursos de um 
rico herdeiro e de uma "pessoa em situação de rua”, homeless ou menino da rua; mas não fecharei a porta a uma hipótese por causa dos meus a prioris, a conferir).

De qualquer modo, a Biografieforschung é tão conhecida na Alemanha que ganhou um espaço na Wikipédia. $\mathrm{O}$ artigo, de quatro páginas, é em alemão, uma língua difícil que não domino totalmente. Contudo, acredito ter compreendido o essencial. A ideia geral - muito "societológica" - é que a modernidade contemporânea (a hipermodernidade, dirão alguns) corroeu ou fez desaparecerem a ideia e a existência mesma de "biografias normativas", de alguma maneira traçadas de antemão nos percursos biográficos: uma vida de operário em uma grande fábrica, uma vida de um camponês, uma vida de um pequeno comerciante, de funcionário público, ou de proprietário rentista. Todas essas "figuras" de "destinos sociais" muito estáveis desapareceram ou estão desaparecendo a olhos vistos. A hipermodernidade pede que cada um e cada uma construam seu próprio percurso de vida no seio de um contexto societal que se tornou cambiante e imprevisível. Cada um se soma para ser o condutor, o "sujeito" de seu próprio percurso. Assim, tornou-se interessante para os sociólogos observar - por meio de relatos de vida - como cada um(a) lida com isso para tentar obter controle sobre seu percurso de vida. $\mathrm{O}$ instrumento de observação seria portanto o relato de vida, pois ele permitiria ter acesso - por meio de um exame hermenêutico aprofundado do texto das entrevistas narrativas - aos Sinnstrukturen, às estruturas latentes de significação trazida por um ou outro indivíduo.

$\mathrm{O}(\mathrm{a})$ autor(a) do artigo se esforça para apontar o que eu chamaria de status - enquanto dado, data - de um relato de vida. Depois de ter lembrado que os sociólogos da Escola de Chicago haviam juntado todo tipo de documentos para procurar saber o que havia sido o percurso real de tal ou tal indivíduo, subentendendo que era em vão, o(a) autor(a) escreve o seguinte: "Hoje [...] é cada vez mais suposto que o percurso de vida de uma pessoa entrevistada não pode ser reconstruído, pois suas experiências são sempre interpretadas por meio de suas próprias percepções; e 'combinadas' em sua memória em função de um arranjo global. Portanto, o sujeito da Biografieforschung não pode e não deve ser nada além da biografia tal como é percebida e memorizada - e não o percurso ele mesmo" ("Biografieforschung”. Wikipédia, minha tradução). Não encontramos nenhum sinal, nesse artigo da Wikipédia alemã, de ideia de recorrências (nas descrições dos percursos individuais encontrados no mesmo nível sociocultural, assim, o lugar do operário, do padeiro) e do momento de saturação (quando da repetição das recorrências, mas também a elaboração de um modelo mental de possíveis lógicas e processos sociais out there que permitiriam explicar as recorrências).

Enfim, aqui nos encontramos exatamente no meio de uma encruzilhada. A constatação, unanimemente compartilhada, é que não se pode determinar a priori o que um relato de vida diz, segundo a fórmula jurídica bem conhecida: "toda a verdade, 
e apenas a verdade". Pessoalmente penso que, quando alguém relata sua vida, ele/ ela é irresistivelmente conduzido a falar a verdade, simplesmente por causa da necessidade da coerência do relato, é muito mais fácil do que mentir... Mas é verdade que não posso comprová-la. Partimos, portanto, da constatação de que o entrevistador, o pesquisador, o sociólogo ou outro não possui os meios de verificar cada uma das asserções (statements) do entrevistado. Aqui se situa exatamente o cruzamento dos caminhos entre duas diferentes maneiras de utilizar os relatos de vida.

Uns dirão: "Já que não possuímos nenhum meio de verificar a objetividade do que diz o entrevistado, abandonemos simplesmente a pesquisa da objetividade e interessemo-nos pela única coisa que temos: o que ele ou ela diz. Faremos, portanto, a aposta de que essa é a expressão direta e sincera da sua subjetividade, e a tomaremos como objeto de reflexão; concentremo-nos sobre ela, pois é a única realidade (discursiva) de que dispomos". Tal é a posição da maioria - todas as disciplinas confundidas - dos pesquisadores que trabalham sobre os relatos de vida.

Tal posição epistemológica convém perfeitamente aos psicólogos, que se interessam pelo que existe na mente das pessoas; assim sem dúvida quanto aos psicólogos, aos sociolinguistas, aos literatos, aos instrutores de supletivos, aos trabalhadores sociais e aos educadores. Pois pouco lhes importa "o que realmente aconteceu" no passado; o que lhes importa é o que a pessoa considerada pensa hoje.

Existem, porém, duas categorias de pesquisadores que resistem ao consenso em torno da rejeição da objetividade: são os sociólogos “objetivistas” (dos quais faço evidentemente parte) e os historiadores que, como o inglês Paul Thompson, um dos fundadores da oral theory, ao constatar a ausência total de fontes documentais sobre tal ou tal atividade do passado (que não deixaram escritos), fazem história oral, interrogando pessoas idosas sobre sua infância ou sua juventude. Ora, esses encontraram uma solução ao "problema" da veracidade dos relatos de vida: basta coletar vários junto às pessoas que viveram na mesma época e no mesmo "lugar" socioestrutural. Orientados - pelo entrevistador - para as descrições de suas condições de trabalho e/ou de vida, seus relatos irão necessariamente coincidir, e as recorrências de uns em relação aos outros serão numerosas. E se um dos relatos é fantasiado - produto de um espírito mitômano -, aparecerá muito rapidamente como tal na comparação com os outros relatos.

LC e YS: As teorias sociológicas contemporâneas foram formadas com base na mesma distinção fundamental: campo-habitus (Bourdieu) - sistema-ator (Touraine, Crozier) - estrutura-agência (Giddens). Você sugere um nivel intermediário, o de relações subjetivas fortes e duráveis. Você ach a que a binariedade da teoria sociológica não é mais capaz de explicar a complexidade do mundo social? 
DB: Não, eu não iria afirmar isso. Devemos primeiro concordar sobre qual é a boa e fundamental "distinção", o bom par epistemológico, como Bourdieu e Passeron (1999) dizem em O ofício de sociólogo. Após ter duramente criticado os "pares falsos epistemológicos tirados do senso comum" como sociedade/indivíduo, holismo/ individualismo ou objetividade/subjetividade, eles propõem o que acreditam ser o bom par: campo/habitus. Mas esse par é pouco sólido: o conceito de campo tem grandes qualidades; mas o de habitus tem muitos problemas. Ele pode dar conta só de uma parte (relativamente pequena) das ações de qualquer indivíduo ou uma parte das razões que ele/ela tem de agir como ele/ela age.

É o par estruturas/ações que me parece o melhor, o mais estável. Aquele que tem mais probabilidade de uma vida longa. Encontro profundas afinidades com o par formado pelo yin e yang da filosofia chinesa de tao, que passou por séculos e até milênios. É verdade que o tempo tem acelerado consideravelmente desde então, mas essa profundidade histórica constitui para mim uma referência. Giddens (2003) construiu seu enorme esforço de síntese sobre o fundamento desse par epistemológico (em seu livro The constituition of society - A constituição da sociedade). No entanto, acho que ele não sabia como desenvolver o lado da ação na direção certa. Falta-lhe o conceito de curso da ação, que Catherine Delcroix e eu desenvolvemos em dois níveis: a teorização e, especialmente, as enormes diferenças dos possíveis cursos de ação dependendo do meio social (e as quantidades e qualidades dos recursos de que dispõem os atores para desenvolver seus projetos). Estamos terminando um texto sobre esse assunto.

Quanto ao “nível intermediário” das relações interpessoais, sim, ainda considero que é muito importante e, cada vez mais, com a hipermodernidade. Os grandes fundadores - os "clássicos" - não falam muito sobre isso, exceto Simmel. Mas G. H. Mead, o fundador do interacionismo simbólico, só fala disso. Atualmente, muitos sociólogos procuram conceituar as redes (networks) de relações interpessoais. Alguns, como Manuel Castells, pensaram que poderiam encontrar a chave da hipermodernidade (eu não acredito nisso: as relações de classe ainda estão aí, mais centrais e mais "núcleos duros" do que nunca). Outros, como Bruno Latour e Michel Callon, desenvolveram a teoria de atores/redes, ampliando consideravelmente o sentido de ator (incluindo as máquinas) e o de rede. O próprio Bourdieu, um arquiestruturalista, apesar de sua conversão tardia e relativa ao construtivismo, anti-interacionista, purista da teorização sociológica (ansioso por afastar tudo o que seria não apenas psicológico mas também sócio psicológico ou psicossociológico ou da psicologia social), já estava muito interessado, no final dos anos 1960, quando conversei com ele face a face, nas relações sociais; afinal, é ele quem desviou o verdadeiro significado do termo "capital" para aplicá-lo metaforicamente não apenas ao nível de educação (capital cultural) mas às redes de relações ("capital social”). 
LC e Ys: Você chama a atenção para a importância da dimensão temporal no método do relato de vida. Como a reconstrução da estrutura diacrônica das trajetórias individuais pode construir a objetividade narrativa para compreender os processos coletivos?

DB: Eu tenho lidado com a questão da contribuição dos relatos de vida para a consideração da temporalidade e da historicidade dos mesocosmos sócio-históricos que compõem o macrocosmo social (Bertaux, 2014). A oposição objetividade versus subjetividade conduz a uma selva de várias confusões. Isto não é uma boa oposição. Tudo o que eu digo aqui, tudo que escrevo em resposta às suas perguntas, todos os escritos de autores, todos os livros, todos os artigos, todas as palavras são intrinsecamente parte do domínio da subjetividade. Eu pergunto a você qual é a sua nacionalidade. Você me responde, abra aspas: "Eu sou brasileiro". Ок, eu tomo nota; mas é uma resposta subjetiva. Isso implica que éfalso? (porque isso é que implica o fato de opor subjetividade e objetividade!). Na verdade, sua resposta poderia ser falsa. Mas eu acredito em você, eu não preciso ver seu passaporte (minha confiança em você é também subjetiva).

Todo relato de vida é intrinsecamente uma produção subjetiva. Isso não significa que tudo seja falso! A primeira pergunta é saber se o que é dito e/ou contado (em um relato de vida) sobre as datas, os lugares, os eventos, as descrições de situações concretas, as descrições de atos e de cursos de ação, de processos como sequências de situações e ações é factualmente exato. Ou não. Nesse ponto, os qualificadores de factual e de objetivo têm o mesmo significado. Mas a confusão começa quando generalizamos a partir daí. Um relato de vida se exprime principalmente na forma de narrativa. Mas uma história não é reduzida a sequências de fatos (se não, é apenas uma crônica fatual). O narrador deve ligar uns aos outros os fatos, as situações fatuais, os atos resultantes, as razões (subjetivas) que fazem os atores agirem etc. Em outras palavras, o narrador deve propor interpretações dessas sequências. Mas qual é o status de verdade de uma interpretação? Existem interpretações completamente objetivas? Pode-se dizer que algumas são mais "factualmente exatas" do que outras. Podemos chegar a dizer que algumas são, factualmente falando, totalmente exatas. Mas nunca podemos dizer que uma interpretação é totalmente verdadeira. Pense na historiografia, pense na série de trabalhos de historiadores sobre, por exemplo, a Revolução Francesa, ou este ou aquele momento da história do Brasil. A questão nunca se encerra: nas próximas décadas, os novos historiadores voltarão a esses momentos históricos e produzirão novas interpretações sobre eles.

Não devemos confundir as ciências históricas e sociais com as ciências da natureza. Estas últimas podem recorrer a experimentos e, assim, eles puderam descobrir as leis da Natureza, a lei da gravidade, por exemplo. Nesse contexto, pode-se falar 
de explicação no sentido estrito do termo. Estamos lá, com a Natureza inanimada, em um universo completamente diferente daquele da História humana e, para poder falar sobre isso, estamos em um registro bastante diferente. Explicação versus interpretação: esta oposição tem um significado. As explicações cientificas - baseadas em experimentos que podem ser repetidos, reproduzidos, replicados quantas vezes você quiser - são verdadeiras ou falsas. As interpretações de eventos históricos e de fenômenos sociais são mais ou menos plausíveis e levam mais ou menos em conta um maior ou menor número de fatos observados.

LC e Ys: Em relação à amostragem, você destaca a importância da variabilidade dos relatos. Relatos com um único ator ou um pequeno número de atores levantariam dúvidas quanto à credibilidade do processo? Como você resolveu o problema da amostragem com Lioudmilla, uma russa no século, escrito com Véronique Garros (1998)?

DB: Para mim, com minha formação científica, a questão do rigor é central. Mas, ao contrário de muitos sociólogos quantitativos (que não têm formação no espírito ou na história das ciências naturais), aprendi a não confundir a fatualidade dos dados com a objetividade de uma representação sociológica que contém sempre uma grande parte da interpretação; mesmo que sejam estatísticas demográficas simples (porque as categorias a partir das quais as estatísticas são construídas foram construídas elas mesmas por uma série de decisões arbitrárias, como, por exemplo, a distinção urbano/rural).

Quanto ao pequeno livro Lioudmilla, queríamos publicá-lo porque era um verdadeiro testemunho da vida cotidiana na URss. Na época, havia muito poucos. Ele era "representante" ou não dos modos de vida das mulheres de sua geração? Sim, mas não no sentido estatístico. Os contextos que ela viveu e que ela descreve e "conta" existiram historicamente, é tudo o que podemos dizer sobre isso. Mas já é muito.

Sèvres, 8 de janeiro de 2018; e Estrasburgo, 22 de fevereiro de 2018. 


\section{Referências Bibliográficas}

Becker, Howard S. (1982), Art worlds. Art worlds and collective activity. Berkeley, University of California Press.

Bertaux, Daniel. (1977), Destins personnels et structure de classe. Paris, Presses Universitaires de France (PUF).

Bertaux, Daniel. (1978), Destinos pessoais e estrutura de classe: para uma critica da antroponomia. Lisboa, Moraes Editora.

Bertaux, Daniel. (1979), Destinos pessoais e estrutura de classe: para uma crítica da antroponomia. Rio de Janeiro, Editora Zahar.

Bertaux, Daniel \& Malysheva, Marina. (1994), "Le modèle culturel des classes populaires russes face au passage à l'économie de marché”. Revue d'Études Comparatives Est-Ouest, 4 (25): 197 228. Disponível em https://www.persee.fr/doc/receo_0338-0599_1994_num_25_4_2705.

Bertaux, Daniel. (1997), Les récits de vie: perspective ethnosociologique. Paris, Nathan Université; (2016), 3 ed. Paris, Armand Colin.

Bertaux, Daniel \& Malysheva, Marina. (1997), "The cultural model of the Russian popular classes and the transition to market economy". In: Bertaux, D. \& Thompson, P. (eds.). Pathways to social class: a qualitative approach to social mobility. Oxford, Clarendon Press, pp. 25-53. Disponível em http://www.daniel-bertaux.com/textes/russian-popular-classes.pdf.

Bertaux, Daniel \& Garros, Véronique. (1998), Lioudmilla: une russe dans le siècle. Paris, La Dispute.

Bertaux, Daniel. (2014), “Sept propriétés des récits de vie”. In: Ertul, S.; Melchior, J. Ph. \& Lalive D’Epinay, C. (dirs.). Subjectivation et redéfinition identitaire. Rennes, Presses Universitaires de Rennes, pp. 29-52.

Bertaux, Daniel \& Bertaux-Wiame, Isabelle. (1976), Une enquête sur la boulangerie artisanale par l'approche biographique. Subvention C.O.R.D.E.S. n. 43/76, Rapport Final, vol. I. Disponível em http://www.daniel-bertaux.com/textes/bertauxboulangerievol-i.pdf.

“BiografieforschunG". Wikipédia. Disponível em https://de.wikipedia.org/wiki/Biografieforschung.

Bourdieu, Pierre. (1986), "L'illusion biographique". Actes de la Recherche en Sciences Sociales, 62/63: 69-72. Ed. bras.: Bourdieu, Pierre. "A ilusão biográfica”. In: Amado, Janaina \& Ferreira, Marieta de Moraes (orgs.). ([1986] 2006), Usos e abusos da história oral. Tradução de Glória Rodríguez, Luiz Alberto Monjardim, Maria Magalhães e Maria Carlota Gomes. 8 ed. Rio de Janeiro, Editora FGV, pp. 183-191.

Bourdieu, P.; Chamboredon, J.-C. \& Passeron, J.-C. (1999), O oficio de sociólogo. Petrópolis, Vozes.

Catani, Maurice \& Mazé, Suzanne. Tante Suzanne, une histoire de vie sociale. Paris, Librairie des Méridiens, 1982. 
Durkheim, Emile. (1994), As regras do método sociológico. Tradução de Paulo Neves. São Paulo, Martins Fontes.

EHrenreich, Barbara. (1987), The hearts of men: American dreams and the flight from commitment. Nova York, Anchor.

Giddens, Antony. ([1989] 2003), A constituição da sociedade. 2 ed. São Paulo, Martins Fontes.

Glaser, Barney G. \& STRauss, Anselm L. (1967), Discovery of grounded theory: strategies for qualitative research. New Brunswick/Londres, Aldine Transaction.

JUAN, Salvador. L'école française de socioanthopologie. Auxerre, Sciences Humaines Editions, 2015.

LAHIRE, Bernard. (1998), L’homme pluriel: les ressorts de l'action. Paris, Nathan (Essai \& Recherche, Sciences Sociales).

LEWIs, Oscar. Les enfants de Sanchez:autobiographie d'une famille mexicaine. Tradução do inglês por Celine Zins. Paris, Gallimard, 1963.

Poulantzas, Nicos. (1975), As classes sociais no capitalismo de hoje. Rio de Janeiro, Zahar.

RAGIN, Charles C. \& BECKER, Howard S. (1992), What is a case? Exploring the foundations of social inquiry. Cambridge, Cambridge University Press.

Thomas, William I. \& Znaniecki, Florian. (1918/1996), The Polish peasant in Europe and America: a classic work in immigration history. Chicago, University of Illinois Press.

Texto recebido em 4/7/2019 e aprovado em 27/7/2019.

DOI: 10.11606/0103-2070.ts.2020.159702.

LuCiano Rodrigues Costa é doutor em ciências sociais pela Unicamp com pós-doutorado pelo CNAm (Conservatoire National des Arts et Métiers). Professor do Departamento de Economia Rural e do programa de Pós-graduação em Extensão Rural da Universidade Federal de Viçosa, DER/Ufv. É autor de vários artigos e do livro Trabalhadores em construção: mercado de trabalho, redes sociais e qualificações na Construção Civil (2013). É pesquisador na área de trabalho, relações de trabalho, educação, qualificação profissional, com estudos sobre o setor da Construção Civil. E-mail: luciano.costa@ufv.br.

Yumi Garcia dos Santos é socióloga e professora da Universidade Federal de Minas Gerais. Defendeu sua tese de doutorado em cotutela entre a Universidade de São Paulo e a Université Paris 8 Saint-Denis (França). Tem desenvolvido pesquisas sobre a inserção das mulheres no mercado (no sentido amplo, que entrelaça trabalho, política, cultura e religião) no nordeste de Minas Gerais. Suas publicações mais recentes discutem as novas políticas sociais no Brasil, sua dimensão local e suas implicações nas relações de gênero; mobilidade social e trajetórias e a persistência das desigualdades de gênero e raça/etnia. E-mail: yumigarciasantos@gmail.com. 